\title{
Synthetic Biology as a Technoscience: The Case of Minimal Genomes and Essential Genes
}

\author{
Massimiliano Simons, Ghent University \\ Massimiliano.simons@ugent.be
}

Department of Philosophy and Moral Sciences, Blandijnberg 2, BE-9000, Ghent

\begin{abstract}
This article examines how minimal genome research mobilizes philosophical concepts such as minimality and essentiality. Following a historical approach the article aims to uncover what function this terminology plays and which problems are raised by them. Specifically, four historical moments are examined, linked to the work of Harold Morowitz, Mitsuhiro Itaya, Eugene Koonin and Arcady Mushegian, and J. Craig Venter. What this survey shows is a historical shift away from historical questions about life or descriptive questions about specific organisms towards questions that explore biological possibilities: what are possible forms of minimal genomes, regardless of whether they exist(ed) in nature?

Moreover, it highlights a fundamental ambiguity at work in minimal genome research between a universality claim and a standardization claim: does a minimal genome refer to the minimal gene set for any organism whatsoever? Or does it refer rather to a gene set that will provide stable, robust and predictable behaviour, suited for biotechnological applications? Two diagnoses are proposed for this ambiguity: a philosophical diagnosis of how minimal genome research either misunderstands the ontology of biological entities or philosophically misarticulates scientific practice. Secondly, a historical diagnosis that suggests that this ambiguity is part of a broader shift towards technoscience.
\end{abstract}

Keywords: Minimal genome ; essential gene; Mycoplasma ; Craig Venter; synthetic biology ; technoscience

\section{Competing interests}

No competing interests to declare.

\section{Funding}

This work was supported by the Research Foundation Flandres (FWO), Grant nummer:12J8820N.

\section{Acknowledgements}

A previous version of this paper was presented at the CEFISES seminar on Artifacts of Scientific Practice at Louvain-la-Neuve on 26 February 2020. I want to thank Charles Pence for the invitation and the audience for its thoughtful comments and questions. I also want to thank the two anonymous reviewers and Emily Herring for their helpful comments and suggestions. 


\section{Introduction}

On 20 May 2010 the J. Craig Venter Institute announced the synthesis of the "first synthetic bacterial cell". Publishing their results in Science they baptized this first construct M. mycoides JCVI-syn1.0 (Gibson et al., 2010). This announcement caused numerous responses and newspaper articles, both to praise and to criticize it (Pennisi, 2010; Bedau et al., 2010). In popular press the organism was named 'Synthia' and made the cover of several major newspapers in the United States and featured in about 4,800 other international news outlets. What the Venter group in fact achieved was a proof of concept of the transplantation of the adapted and synthesized Mycoplasma myciodes genome in a Mycoplasma capricolum recipient cell, out of which the original genome was removed. The cost of this endeavour was around $\$ 40$ million dollars.

Although for outsiders this announcement was a surprise, the Craig Venter group situated its achievement within a broader tradition, namely that of minimal genomes: "Our interest in synthesis of large DNA molecules and chromosomes grew out of our efforts over the past 15 years to build a minimal cell that contains only essential genes." (Gibson et al., 2010, p. 52) But what is precisely meant by a minimal cell or a minimal genome ${ }^{1}$ And what are essential genes? The literature on minimal genomes, and the work of the Craig Venter group in particular, is brimming with unclear references to abstract and even metaphysical notions such as minimality, essentiality and necessity. But what do these terms entail? Within the literature brief, but unhelpful definitions are given: "A minimal cell is usually defined as a cell in which all genes are essential." (Hutchison et al., 2016, p. 8) On its turn, essential genes are defined as "genes indispensable for survival of living organisms" (Juhas, 2016, p. 416).

This paper aims to clarify how these concepts are used and understood in the literature on minimal genomes. The approach, however, will not be one of conceptual analysis, but rather a historical one. Inspired by historical epistemology (Rheinberger, 2010) and arguments about the 'sedimentation' (Husserl, 1935) and the 'entrenchment' (Goodman, 1965) of concepts, the methodological starting point is that the meaning and use of concepts can best be understood by looking at how they have historically been introduced and embedded in the literature. The argument is not that their original use carved its meaning and use into stone, which would entail a genetic fallacy, but rather that the history of concepts highlights a number of shifts and choices that are still shaping its current meaning and use.

The goal therefore is to trace the history through which the question of minimal genomes became linked and integrated in a field as foreign to it as synthetic biology. As will be shown, while the field of minimal genomes can be traced back to the 1950s, synthetic biology is typically seen as a discipline that came into being only in the 2000s. For early minimal genome scientists, such as Harold Morowitz, the problem of minimal genomes was rather understood as a historical and evolutionary one: the aim was to discover the simplest and most original genome in the history of life on Earth. This research programme on the origins of life was only later taken up by synthetic biology and, as I will argue, in

\footnotetext{
${ }^{1}$ Both in the communication towards the press, as well as in the article, the term 'minimal' and 'synthetic' cell is systematically used, whereas in reality the project concerned the synthesis of a minimal genome, since nothing but the DNA was synthesized. In the article itself, the Venter group is aware of the difference: "We refer to such a cell controlled by a genome assembled form chemically synthesized pieces of DNA as a 'synthetic cell,' even though the cytoplasm of the recipient cell is not synthetic." (Gibson et al., 2010, p. 55) This translation of the problem of minimal cells into a problem of minimal genomes is a significant assumption in the field.
} 
that process fundamentally reconceptualised. ${ }^{2}$ It is my claim that it is in the light of these shifts that the meaning and use of concepts such as essentiality should be understood.

More specifically, this will be done by an analysis of four historical moments in the history of minimal genomes. In the first section, I will look at the work of Harold Morowitz who initiated the study of minimal cells in the 1950s and how his work was embedded in the broader history of mycoplasma research and Cold War efforts to sponsor theoretical biology and exobiology (section 2). Then, two shorter historical cases are discussed, namely an influential paper by Mitsuhiro Itaya (1995) and the influence of comparative genomics on the field, illustrated by the work of Eugene Koonin and Arcady Mushegian (section 3). To conclude the historical part, the work of the Craig Venter group will illustrate the transformation of minimal genome research by synthetic biology (section 4). ${ }^{3}$

In the fifth section the concepts of minimality and essentiality will be revisited. Informed by these histories, it will be argued that research on minimal genomes suffers from a fundamental ambiguity. The notion 'minimal genome' can either refer to an abstract claim about which genes are universal and necessary for any living system (the universality claim); or it can refer to the practical claim about the genes required for a biological system to function reliably and uniformly within a desired, often artificial context (the standardization claim). Most synthetic biologists do not distinguish between these claims.

This ambiguity can provoke two different responses. First of all, a philosophical diagnosis can be formulated (section 6). I will stick to two philosophical critiques, namely a metaphysical one about how life should be conceptualized, inspired by Georges Canguilhem and John Dupré, and an epistemological one about how scientific practices in the life sciences should be understood, following Bruno Latour and Bas van Fraassen.

A second response, however, highlights how this tension is not just a product of ignorance, but can be understood as a sign of a broader shift in the 'experimental system' (Rheinberger, 1997) at work in this field. In section 7, I propose the following hypothesis: that this historical shift in experimental systems must be understood in light of synthetic biology being a technoscience (Nordmann, 2015; BensaudeVincent and Loeve, 2018). Technoscience here refers to a collection of recent scientific disciplines that are mainly focused on the explorations of possibilities, rather than actualities. In the case of biology, this refers, for instance, to the possible origins of life or possible minimal cells, rather than their actual, terrestrial counterparts. It is through new technologies of synthesis, and the related experimental systems, that older speculative and historical questions about the origins of life and minimal genomes are translated into accessible experimental questions that can be meaningfully pursued.

\section{Morowitz and the search for the minimal genome}

\footnotetext{
${ }^{2}$ A similar process has occurred in the related historical question of the chemical origins of life (Miller, 1953; Bernal, 1967). In recent synthetic protocell biology this historical question was taken up, but similarly redefined as a question about universal biology (Mann, 2013; Luisi, 2016; Simons forthcoming): what are the chemical conditions for any form of life whatsoever, regardless of how it came into being on Earth?

${ }^{3}$ Some other research programmes in minimal and synthetic genomes are thus intentionally left out. For instance, in recent years a new influential subfield is that of synthetic yeast, aiming to synthesize all the chromosomes of a yeast cell (see Richardson et al., 2017; Szymanski and Calvert, 2018). I also thank one of the reviewers for pointing out that in the 1990s Morowitz influenced the then computer engineer Tom Knight to develop his own form of synthetic biology. Since Knight's work is the example of another form of synthetic biology, mainly inspired by engineering, this part of the historical reception of Morowitz will be left aside here as well.
} 
Harold Morowitz (1927-2016) was an American biophysicist, mainly known for his work on thermodynamics in biology and the origins of life. At the end of the 1950s, he was one of the beneficiaries of the American government's interest in the origins of life and exobiology, as an off spin of the Space Race during the Cold War. It was believed that the risk of astronauts to encounter extraterrestrial lifeforms in space, even in the form of microscopic organisms, was real. It was therefore important to understand the molecular basis of minimal lifeforms, whose characteristics would be shared by any encountered extraterrestrial lifeforms. In addition, after the Soviet victory in the Space Race by the launch of Sputnik in 1957, the American government saw in exobiology a new field where they had to compete, and could possibly beat, Soviet scientists, such as Alexander Oparin, who until then had dominanted the study of the origins of life.

Besides other famous cases such as Stanley Miller, it was also Harold Morowitz who gained institutional support from NASA in his research. In 1961, for instance, he received a NASA Exobiology Grant. A year later NASA funded the Committee for Theoretical Biology, with Morowitz as one of its founding members. Within this context Morowitz' interest in the minimal cell began to take shape. As he later reported, it was "[i]n the late 1950s [that] a group associated with my laboratory began to focus on the question: What is the smallest autonomous self-replicating entity?" (Morowitz, 1984, p. 750) At that time, it was far from clear where to look for this smallest biological entity. Earlier attempts to find the minimal living organism, for instance by J. B. S. Haldane, H. J. Muller or the famous Delbrück phage group pointed towards bacteriophages as potential candidates (Cairns, Stent \& Watson, 1992; Fry, 2006). However, already in the 1940s, Thomas Anderson showed by use of an electron microscope that a bacteriophage was not an elementary particle of biology, but a complex being in its own right (Morange, 2000, p. 45).

Morowitz thus had to look elsewhere. But how does one find the smallest organism out there? Morowitz' answer was simple: by mail. He sent "a series of letters to microbiologists around the world asking for the organism of choice." (Morowitz, 1984, p. 750) Moreover, he skimmed through reference works such as Bergey's Manual of Determinative Bacteriology and the American Type Culture Collection looking for species whose names included Latin terms such as parvulus, referring to the small size of the cells. The rationale behind this search, as Morowitz later explained, was the following:

The reason for our quest was to find a paradigm organism to synthesize all the newly emerging knowledge in the field of molecular biology. Just as the hydrogen atom, the smallest and simplest member of the periodic table, had served to sharpen many of the fundamental questions of spectroscopy and quantum mechanics, so, we reasoned, would a minimum biological system play an analogous role. The smallest system was being sought because it would probably be the simplest. (Morowitz, 1984, p. 750)

Out of this research one promising candidate came forward: the genus of mycoplasma, or as it was known at the time, PPLOs.

By that time, mycoplasmas already had a turbulent history in biological research (see Razin and Hayflick, 2010). Originally detected and named by the German botanist Albert B. Frank (1839-1900) in 1889, he saw them as a type of fungus-infection of plant cells, resulting in an altered state of their cytoplasm. As a result, Frank named them Mycoplasma, from the Greek $\mu$ úkns, mykes (fungus) and $\pi \lambda \alpha \dot{\sigma} \mu \alpha$, plasma (formed). Soon enough, other plant physiologists such as Jakob Eriksson (1848-1931) adopted this name and further debated the nature of this plant pathology.

It was only in the 1920s that mycoplasma was first used as a genus term, namely by Julien Nowak. At the same time, however, entities with similar behavior were also being discovered as the cause of a number of animal diseases, such as agalactia in sheep. What was noted was how similar they were in 
their effects to pleuropneumonia in cattle, and all these original mycoplasmas became therefore known as pleuropneumonia-like organisms, often abbreviated as PPLO (see Morowitz, 2011).

It was only in the 1950s, around the time when Morowitz was starting his search for the minimal cell, that the identity of PPLOs was starting to get fixed. In 1959, for instance, a conference on 'The Biology of the Pleuropneumonia-like Organisms' was held in New York, with one of the main questions being whether PPLO's were L-forms or not. L-forms referred to another small biological entity, first isolated in 1935 by the microbiologist Emmy Klieneberger-Nobel (1892-1985), and named after the institute she worked at, the Lister Institute in London. Klieneberger-Nobel already successfully argued that PPLOs were to be differentiated from other organisms by a lack of a cell wall, but this characteristic was shared by the L-forms she discovered.

In the aftermath of the conference, however, it was shown that though both lacked cell walls, L-forms used to have one, but lost it due to external intervention, whereas PPLOs never had a cell wall to begin with. The name PPLO was moreover dropped for mycoplasma in the 1960s and mycoplasmas were identified as a genus of parasites, ranging from mammals to plants, being part of the class Mollicutes, distinguished by the absence of a cell wall. They consist of nothing but a lipoprotein membrane, ribosomes and free-floating DNA. A feature that caused a lot of confusion around mycoplasmas was their size, which allowed them to evade traditional bacteria filtration techniques. As Morowitz later recalled, in the beginning of his investigation of mycoplasmas, he received numerous phone calls from colleagues complaining about mycoplasma contamination "and some were accusatory, as if our sloppy ways were spreading these organisms around New Haven." (Morowitz, 2011, p. 102)

Though the minimal size was what initially led Morowitz to mycoplasma, his conception of minimality transformed in the 1960s, since molecular biology became prominent and highlighted the centrality of DNA (see Morange, 2000). As a consequence, "[w] ith the emergence of molecular biology, the object of the search shifted from the smallest organism to that with the smallest genome." (Morowitz, 1984, p. 750) But surprisingly, the genome of mycoplasmas proved equally small, though complete genome sequences were not available at that time. Genome size was rather estimated through different means, for instance its weight, indicating that mycoplasma genomes were indeed very small (Maniloff and Morowitz, 1972).

Based on this, Morowitz believed that mycoplasma was the minimal cell he was after, i.e. it was literally the simplest organism to be found with the absolute minimal requirements of life. "All the complexity of molecular biology is seen in the mycoplasmas, and this must mean that the subtle sophistications seen in the biochemical structures and mechanisms are not evolutionary additions but constitute the fundamental requirements of all biological systems." (Maniloff and Morowitz, 1972, p. 284) Mycoplasma thus provided an answer to a historical and evolutionary question, namely about the simplest form of life that existed, and still exists, on Earth.

However, already in the 1960s the classification of mycoplasmas within taxonomy shifted. The hypothesis was proposed that mycoplasmas were 'degenerate bacteria': bacteria which were more complex in the past, but had deleted genes no longer required in their parasitic environment. Morowitz, however, disagreed. He was convinced that "the mycoplasma is primitive" and that its " $5 \times 10^{9}$ daltons of DNA [with 1 dalton = $1,67 \times 10^{-24}$ grams] represents a primitive genome (which we shall designate a 'genesistron') and subsequent evolution occurred by DNA doubling leading to the $10^{9}$ daltons DNA of the Acholeplasma genus of mycoplasma." (Wallace and Morowitz, 1973, pp. 121-122) He moreover suggested that mycoplasma might have been the ancestor of both prokaryotic and eukaryotic cells, coining the term of 'protokaryote' for mycoplasmas. 
Nonetheless, the degenerate bacteria hypothesis gained ground, especially due to the work of Carl Woese in the 1970s, who revolutionized traditional taxonomy based on an analysis of ribosomal RNA, famously resulting in the novel classification of Prokaryotes, Eukaryotes and Archaea. Woese's analysis also hinted that mycoplasmas were related to organisms with more complex genomes, which had however deleted numerous genes throughout their history. Morowitz remained unconvinced. In the 1980s, for instance, he still argued that the genus mycoplasma, or at least its class mollicutes, contained the primitive cell:

Let me note some properties we would be likely to ascribe to a primitive cell on an a priori basis. 1) It would be wall-less. 2) It would have a minimum genome. 3) It might use a nondegenerate code and could thus have an extreme base ratio - say $23 \% \mathrm{G}+\mathrm{C}$. 4) It would have a rather simple if inefficient - metabolism. If that description begins to sound familiar, then keep an open mind about the evolutionary position of the Mollicutes. (Morowitz, 1984, p. 752)

Morowitz remained committed to the view that mycoplasmas were literally the minimal genomes and could shed a light on the theoretical foundations of molecular biology, not due to "the unusual features of mycoplasmas, but the fact that they are so ordinary in spite of a genome of $5 \times 10^{8} \mathrm{Da}$." (Morowitz, 1984, pp. 752-753) He would soon, however, find himself isolated in this stance when other research programmes in minimal genomes came into being.

\section{Minimal genomes and comparative genomics}

The theme of finding the minimal genome took new forms in the 1990s. One early and influential example was the work of the Japanese geneticist Mitsuhiro Itaya, especially his 1995 paper. As the title makes clear, the paper aimed to give "an estimation of minimal genome size required for life" (Itaya, 1995). Similar to Morowitz, his motivation was historical: "Is the current structure of the bacterial genome a historical accident or are there selecting forces for a particular order and arrangement of the genes on the chromosome?" (Itaya, 1995, p. 257)

Itaya focused on one bacterium in particular, but not mycoplasma. Instead his paper was concerned with Bacillus subtilis. But rather than to claim that the genome of $B$. subtilis was the minimal genome, Itaya conceived the minimal genome as an abstract entity. It was not to be found in any particular organism, but rather deduced from more complex genomes, based on the idea that not all genes of $B$. subtilis are required by the organism to function. "Supposing that there is a limited number of 'indispensable' genetic loci for bacteria, can the least genetic material or the size of a hypothetical minimal genome be deduced?" (Itaya, 1995, p. 257) The method Itaya followed was one of statistical extrapolation. His paper investigated 79 randomly selected chromosomal loci by mutagenesis. Only at six loci did mutations prevent any colonies from forming. Based on this result, Itaya extrapolated that the minimal genome would situate itself somewhere between 318 and 562 kilobases (kb).

Itaya's paper was significant, mainly because it showed a way to study minimal genomes without relying on mere descriptions of actual organisms and their genomes. Indeed, one could imagine a whole research program based on this approach, whereby geneticists would systematically use similar statistical extrapolations to theorize the minimal genome size. However, the same year, another paper was published that offered another and more attractive approach to the problem of minimal genomes.

1995 was the year that the paper with the first full genome sequence of a bacteria, namely Haemophilus influenza was published in Science (Fleischmann et al., 1995). Soon enough, other full genome sequences followed, such as those of Mycoplasma genitalium (Fraser et al., 1995), followed by the first eukaryote Sacharomyces cerevisiae (Goffeau et al., 1996) and the first archaeon, Methanococcus jannaschii (Bult et al., 1996). These sequences were part of the rise of genomics and 
the human genome project (see Barnes and Dupré, 2008; Hilgartner, 2017). But it would also have a profound effect on how the project of finding the minimal genome was tackled.

Two important authors for this shift are Eugene Koonin and Arcady Mushegian, who published multiple papers, often together, on the topic of minimal genomes. According to them, "[w]ith the advent of these sequences, the construction of a minimal gene set sufficient for sustaining cellular life and reconstruction of the genome of the last common ancestor of bacteria, eukaryotes, and archaea become realistic, albeit challenging, research projects." (Koonin and Mushegian, 1996, p. 757). The genome size of mycoplasmas was still on the agenda, but "there is no evidence that it is actually the minimal requirement" (Koonin and Mushegian, 1996, p. 759). Instead, and as an alternative both to the descriptive approach of Morowitz and the statistical approach of Itaya, complete sequencing opened the methodological path of comparative genomics:

Our logic in deriving the minimal gene set was straightforward. It is unlikely that any genes, except those that are indispensable for cell function, could have been conserved through the 1.5 billion years or more separating $H$. influenza and $M$. genitalium from their last common ancestor, given that the evolution in both lineages has been replete with gene elimination. Therefore, the orthologous genes of the two bacteria should comprise the core of the minimal gene set. (Mushegian and Koonin, 1996, p. 10269)

But, as the term 'orthologous' already suggests, the method of comparative genomics was not devoid of problems of its own. A first one was the problem of nonorthologous gene displacement (NOD). Comparing genes was not that simple, since the same genetic function can be performed by genes unrelated by descent, socalled nonorthologous genes. Two different genes could be present in the compared organisms with a similar but non-identical function, both being required for survival but not identical.

One solution for this was gene disruptions or so-called gene knockouts: you disable a gene and see whether the cells from that particular strand would still grow. However, such knockout experiments caused new puzzles. On the one hand they showed that some genes initially deemed indispensable could be knocked out and were thus not "universal genes" (Koonin, 2000, p. 99). On the other hand, some genes that could individually be disabled could not be knocked out simultaneously. This issue was called synthetic lethality: while the genes were dispensable, when considered separately, when they were knocked out together this proved lethal to the cell. Genes could thus be 'mutually inclusive', "adding a further dimension to the study of the minimal genome" (Smalley et al., 2003, p. 7).

Finally, since the ambition of authors such as Itaya, Koonin and Mushegian was to find a universal minimal genome, not restricted to one particular organism, there was also the problem of the environment. Soon enough, it was clear that to speak of minimal genome in an abstract manner was problematic without also specifying the environment in which that specific genome embodied the minimal requirements. Often, this environment was in fact a very artificial laboratory setting in which the cells could thrive. As Koonin, for example, frames it:

The idea of a minimal gene set refers to the smallest possible group of genes that would be sufficient to sustain a functioning cellular life form under the most favourable conditions imaginable, that is, in the presence of a full complement of essential nutrients and in the absence of environmental stress. (Koonin, 2000, p. 100)

\section{Craig Venter and 'proof by synthesis'}


This is the context in which the Craig Venter group started to work on minimal genomes in the 1990s. In fact, Venter was at that time already a notorious figure, among others due to his controversial ambition to patent sequenced genes in the early 1990s (Roberts, 1991) and his role in the Human Genome Project, where he claimed that he could sequence the human genome faster by private means, creating the company Celera Genomics to do so (see Hilgartner, 2017).

Craig Venter also played a role in several of the early complete sequences of genomes, such as that of H. influenza (Fleischmann et al., 1995), M. genitalium (Fraser et al., 1995) and M. jannaschii (Bult et al., 1996). His team even framed this research in terms of minimal genomes: "A survey of the genes and their organization in $M$. genitalium permits the description of a minimal set of genes required for survival." (Fraser et al., 1995, p. 400) In addition, it was also the Venter group that introduced the terminology of essential genes to describe the set of genes of the minimal genome:

One important question posed by the availability of complete genomic sequences is how many genes are essential for cellular life. We are now in a position to approach this problem by rephrasing the question 'What is life?' in genomic terms: 'What is a minimal set of essential cellular genes?' (Hutchison et al., 1999, p. 2165)

It is in this 1999 paper that the Venter group also faces the NOD problem mentioned above, leading them to develop their own knockout technique called 'whole transposon mutagenesis', mainly developed by Clyde Hutchison (Marshall, 2009, pp. 1121-1122). This method inserted transposons in the genome at random locations in order to see which cells would survive the insertions and deduce which genes were essential. ${ }^{4}$

Although this method could solve the problem of NODs, it did not solve that of synthetic lethality. But whereas previous papers merely recognised that problem without offering any solutions, the Venter group advocated one particular solution: proof by synthesis. The only way to test whether multiple genes were collectively essential or not "would be to produce reduced genomes by chemical synthesis and introduce them into cells to test their capacity to provide the essential genetic functions for life." (Gibson et al., 2008, p. 1215)

The Venter papers published in the 2000s embody each of the different steps towards this research goal. It started with the synthesis of the genome, not of a bacterium, but of the bacteriophage $\Phi \times 174$. In this 2003 paper they also elaborate on the logic behind the proof by synthesis methodology, inspired by synthetic chemistry:

Synthesis of a molecule with the same properties as a naturally occurring compound has traditionally been used as evidence for correctness of a proposed molecular structure. Therefore, it is interesting to consider whether synthesis of an infectious $\Phi X$ genome proves the correctness of the Sanger sequence on which our synthesis was based. (Smith et al., 2003, p. 15444) $)^{5}$

The next stage consisted in showing how the genome of a bacterium could be synthesized as well and subsequently be transplanted into another bacterium. This was done in three steps: first showing that genome transplantation is possible, more particularly from one species of mycoplasma, $M$. mycoides

\footnotetext{
${ }^{4}$ Transposon mutagenesis is a process by which genes can be transferred to the host organism's genome based on transposons, elements of DNA that can shift position in the genome. It was this process that was initially described by the infamous work of Barbara McClintock in the 1940s, eventually leading to her Nobel Prize in 1983 (see Keller, 1983).

${ }^{5}$ This self-description of synthetic biologists in terminology of synthetic chemistry is not particular to the Venter group, but can also be found in the work of other synthetic biologists, for instance the group of Steven Benner (see Yeh and Lim, 2007; Bensaude-Vincent, 2013).
} 
into another mycoplasma, M. capricolum (Lartigue et al., 2007). The next step was the complete chemical synthesis of a genome, namely that of $M$. genitalium, which they baptized M. genitalium JCVI1.0 because they disrupted its antibiotic resistance (for selection purposes) and added watermarks (Gibson et al., 2008). Finally, then, there is the famous 2010 paper in which they combine the previous steps: synthesizing a slightly adapted $M$. myciodes genome and its transplantation to a $M$. capricolum recipient cell (Gibson et al., 2010).

This shift in methodology, away from comparative genomics towards proof by synthesis, highlights how research on minimal genomes became integrated into synthetic biology. However, this transition of minimal genome research into synthetic biology is characterised by more than a methodological shift. Another important change was a partial shift in the rationale behind the research, the purpose to investigate minimal genomes.

In the case of Morowitz, Itaya, Mushegian and Koonin the motivation behind the research was predominantly theoretical. Investigating minimal genomes could shed a light on the foundations of molecular biology or on the historical question of the origins of life. Hardly any practical motivation was mentioned. At best one can find an occasional brief nod to possible antibiotic purposes, since knocking out indispensable genes would be very effective (e.g. Itaya, 1995, p. 259).

In the synthetic biology papers dealing with minimal genomes, a new justification enters the scene, in addition to theoretical one. Although the theoretical justification does not disappear, often the most central rationale of the papers becomes one of biotechnological applications. Or as the Venter group states in their 2007 paper:

It may facilitate construction of useful microorganisms with the potential to solve pressing societal problems in energy production, environmental stewardship, and medicine. Chemically synthesized chromosomes must eventually be transplanted into a cellular milieu where the encoded instructions can be expressed. We have long been interested in defining a minimal genome that is just sufficient for cellular life (Glass et al., 2006; Hutchison et al., 1999) and have advocated the approach of chemically synthesizing a genome as a means for testing hypotheses concerning the minimal set of genes. (Lartigue et al., 2007, p. 632)

This partial shift in emphasis reflected itself in institutional changes. Craig Venter is typically seen as an exemplar of the new 'scientist-entrepreneur' (Shapin, 2008, Chapter 7). Venter was controversially removed from Celera Genomics in 2002. The same year, he founded the Institute for Biological Energy Alternatives (IBEA), investigating how microorganisms could be used to create fuels or remove carbon dioxide from the air. In 2005, Venter created a new company, Synthetic Genomics Inc. (SGI), followed in 2006 by a non-profit genomics research institute, the J. Craig Venter Institute (JCVI).

But this shift is not particular to Craig Venter, but can be found in other synthetic biologists who are interested in minimal genomes as well. An illustrative case is the Japanese project of the Minimum Genome Factory (MGF), initiated in 2001, which justifies itself in similar terms:

A microbe with a 'minimum genome' is expected to exhibit less regulation and therefore to be an ideal platform for a cell-factory system. The goal of this project is to construct such a minimum genome microbe for a cell factory. In this project, the $4.6 \mathrm{Mbp}$ genome of Escherichia coli K-12 has been successfully reduced to $3.6 \mathrm{Mbp}$. (Mizoguchi et al., 2007, p. 157)

Mycoplasmas are thus abandoned for E. coli, arguing that a full synthesis from the bottom up is not the most efficient and desirable way, at least when the goal is not theoretical (to find the universal minimal set of genes for life) but practical (control and predictability). They therefore advocate a 
genome reduction approach, where the goal is just to disrupt as many inessential genes as possible. "Judging from the current progress with these two approaches, reduction approaches would seem to be a quicker and more realistic way to construct an MGF than synthetic genomics." (Mizoguchi et al., 2007, p. 158)

The result is that some minimal genome research is reconceptualised as the project of building a 'chassis' in synthetic biology (e.g. Sung et al., 2016): a basic and predictable set of genes to which one could subsequently add the desired genes for particular purposes. Or, in the terminology of Venter, a universal recipient cell:

we are conducting new research that has the long-term aim of creating a 'universal recipient cell' that can take any synthetic DNA software customized to create life and create that designated species. [...] In order to create a universal recipient cell, we are in the process of rewriting the genetic code of the mycoplasma cell to enable it to transcribe and translate any transplanted DNA software. (Venter, 2013, p. 188)

Venter even goes so far as to speculate about a next step where they "do away with the need for an existing cell as a recipient for a synthetic genome. Our hope is that we can create synthetic cells, starting with cell-free systems and then adding basic components to construct a complete cell." (Venter, 2013, p. 188)

\section{Minimal genomes and essential genes}

Given these historical episodes, what should we make of all these "essentiality studies" (Lluch-Senar et al., 2015, p. 1)? In philosophy essentialism can mean many things, but the relevant form here seems to be biological essentialism: the claim that species are defined by essential characteristics, such as its genome. Typically, however, this kind of essentialism has been problematized by biologists and philosophers alike as 'predarwinian' (see Hull, 1965). Recently, essentialism has made a comeback with numerous recent defenses of forms of essentialism (Boyd, 1999; Griffiths, 1999; Devitt, 2008). What they all have in common is that they are forms of constitutional essentialism: the view that a class of objects are what they are because each of them possesses a set of properties.

In minimal genome research, however, essentialism seems to be understood differently. First of all, it tends to not so much concern specific species, but life in general. In the philosophy of biology, the debate surrounding what constitutes life is extensive, and includes a meta-debate on whether attempts to define life are meaningful (Machery, 2011; Bich and Green, 2017). These debates do not seem to impact minimal genome research, mainly due to a second difference: it is concerned not so much with what constitutes life, but rather with its operational requirements, what properties allow the cell to survive? Rather than asking what the necessary properties for something to be considered alive are, it asks what cannot be missing for a bacterium to survive and function? It is thus not a constitutional essentialism, but rather an operational essentialism.

This operational essentialism, however, carries with it a number of confusions. We have seen that within its historical development, research on minimal genomes became framed as a search for the essential genes of an abstract minimal genome, somewhere hidden in existing biological organisms. In its search, however, numerous problems came to the surface: Where and how to look for minimal genomes? What to do about NODs? How to deal with synthetic lethality? Although most problems were dealt with, one remained, namely that of the environment of minimal genomes. The literature itself is deeply aware of this problem and explicitly acknowledges it: "Minimal genomes are environment-dependent." (Coyle et al., 2016, p. 276) Typically, the implicit environment that these papers assume is that of the laboratory: 
The hypothetical 'modern' cell would be constructed from the basic molecular machinery of today's organisms, and would exist in an optimum environment (described as a medium containing ample amounts of all necessary nutrients at a constant temperature and $\mathrm{pH}$ ). In addition, the cell would exist in culture at a low enough cell density that metabolic waste products would be maintained at a low (non-inhibitory) level. (Foley and Shuler, 2009, p. 27)

This assumption, however, has consequences. First of all, it hides the fact that therefore "a plethora of minimal cells may exist." (Delaye and Moya, 2010, p. 1281) Depending on the specific environment, different minimal genomes will be best suited. "Thus, which genes constitute a minimal genome becomes a taxo-specific question, implying that there might be many, quite different, minimal genomes possible." (Huynen, 2000, p. 116) Secondly, it gives a misleading image of how stable and viable this minimal genome is. Although a cell can technically survive without several of these 'inessential genes', its existence is strongly qualified. For example,

the elimination of stress-response genes, determined as dispensable under ideal conditions, results in cell death upon mild changes of temperature or nutrient availability. In addition, the elimination of genes from the toxin/antitoxin or restriction/methylase systems, which are dispensable for simple growth on solid media, would render cells vulnerable to infections by phages or other microorganisms in a natural environment. Thus, minimal cells are fragile and restricted to various ecological niches. (Acevedo-Rocha, 2013, p. 275)

Thirdly, this highlights the implicit equation between minimality, simplicity and originality: that which is the smallest is also the simplest and the most original. This can be problematized through counterexamples. Take the practice of writing a text, such as an academic article. Writing a text with less words is typically the end of a long process and often indicates a higher complexity. As the famous quote by Blaise Pascal goes: "I'm sorry I wrote you such a long letter; I didn't have time to write a short one." Similar examples could be given for building a house or playing a piece of music. And in fact, the history of mycoplasmas suggests the same: they are so simple, not because they were the most original ones, but because they were the end product of long process and linked to a specific, highly complex parasitic environment in which they could thrive. Minimality thus not necessarily implies simplicity, but might rather result in an outsourcing of the complexity from the cell to its (artificially sustained) environment.

So, how do minimal genome researchers deal with the problem of the environment? In contrast to the other issues, there is no clear-cut technical or experimental solution. Instead, what we find is a number of proposed theoretical solutions centring around a simple idea, namely to theoretically split up the genome in different parts. Possible candidates are distinctions between essential genes and context genes (Peterson and Fraser, 2001); a pan-genome consisting in a paleome and a cenome (Danchin, 2012); core versus accessory essential genes (Juhas, 2016; Tarnopol et al., 2019); or splitting up a hard, semihard and soft minimal genome (Baby et al., 2018).

Although each proposal subtly differs, the distinctions proposed often split the genome in different gene groups: genes that are universally essential (e.g. paleome, core essential genes, (semi)hard minimal genome), genes essential for specific contexts (e.g. soft minimal genome) or specific organisms (e.g. accessory essential genes) and, finally, inessential genes (e.g. cenome). This strategy thus entails a theoretical retreat: to save the research program of minimal genome, parts of the genome are relinquished in order to keep the idea of a truly minimal genome alive, somewhere hidden even deeper in the cell.

To complicate things even further, in recent papers another category is introduced, namely that of quasi-essential genes (Tarnopol et al., 2019; Breuer et al., 2019). This category was introduced by the 
Venter group in their latest paper where they announced the synthesis of JCVI-syn3.0, an updated synthetic minimal genome. The reason for its introduction is JCVI-syn2.0, an entity which never made it in print, but 'died' in the lab. When they synthesized JCVI-syn2.0 with only essential genes it failed to grow and the Venter group initially could not understand what went wrong. The solution resided in this intermediate category of non-essential genes:

In addition to essential and nonessential genes, there are many quasi-essential genes, which are not absolutely critical for viability but are nevertheless required for robust growth. Consequently, during the process of genome minimization, there is a trade-off between genome size and growth rate. JCVI-syn3.0 is a working approximation of a minimal cellular genome, a compromise between small genome size and workable growth rather for an experimental organism. (Hutchison et al., 2016, p. 1414)

This category has subsequently been taken up by other research groups, but it highlights once again the underlying tensions about the meaningfulness of minimal genome talk. For instance, Tarnopol et al. introduces quasi-essential genes as "genes required for an organism to meet an arbitrarily set maximum doubling time, but that might not be necessary if that parameter were removed" $(2019, \mathrm{p}$. 2537). Quasi-essential genes are only essential based on arbitrarily set standards, related to specific human goals, rather than universal or necessary principles.

Finally, besides the problem of the environment, there is also a second way in which minimality as a concept is problematic, namely its assumption that even within one environment there would only be one unique set of genes that fulfils the requirement of minimality. But it could fail to be unique not only because of variations in the environment, but also for functional reasons, for there could be several different, but equally minimal sets of genes that could fulfill a particular goal in a particular environment. Again, some researchers are aware of this, but only a minority. They propose to abandon talk about essential genes, instead pleading for things like 'gene niches' (Koonin, 2000) or 'gene persistence' (Acevedo-Rocha et al., 2013). But although they seem to abandon the ambition of finding the essential aspects of living cells, they often reaffirm this ambition on the next level. For instance, Acevedo-Rocha et al. "suggest using metrics of gene persistence as a constructive way to identify the minimal universal functions that support robust cellular life" (2013, p. 273). In that sense, not the minimal set of essential genes, but the minimal set of essential functions becomes the holy grail. But here, once again, the problem of the environment reappears.

These struggles with defining essential genes and their environments highlight a central tension within the field of minimal genome research, namely between two conflicting agendas at work beneath the term of essentiality. A minimal genome can either refer to an abstract and theoretical claim about which genes are universal and essential for any living system whatsoever, regardless of the context. Let us call this the universality claim. On the other hand, a minimal genome can also refer to those genes which are required for a biological system to function reliably and uniformly within a desired, often artificial context. Let us call this the standardization claim.

In many studies these two agendas are, however, not clearly disambiguated. Only recently, some papers have started to explicitly address the tension between both groups:

There are two contending opinions regarding the best cellular chassis. The first group believes that natural, robust cells constitute better chassis [...] due to their complexity, robust cells can thrive in environments where the minimal cell could not grow without meticulous condition or additives in the growth medium. Furthermore, it seems robust cells are capable of faster growth than their minimized counterparts. [...] The second group views the minimal or reduced cell as an ideal chassis for the production of useful products. Among the main advantages of 
cells harbouring only the minimal genome would be the detailed understanding of all genes and their interactions. Consequently, this would allow tighter control of any novel biological pathway introduced into such minimal cell (Juhas, 2016, pp. 420-421)

Similarly, Martinez-Garcia and de Lorenzo contrast an agenda that seeks "to understand what one could call minimal life" with a "second agenda [that] stems not from a basic interest in understanding life, but from a more mundane concern in improving biotechnological processes" (2016, p. 220). As a result, some biotechnologists plainly pick sides and abandon the theoretical ambition to find a universal minimal genome. They opt instead for a top-down genome reduction approach which although it "may not reach a 'true' minimal genome, it is a more pragmatic approach for constructing bioproduction chassis as genome reduction proceeds only up to the point that the minimized strain reaches growth and production yield and rate goals." (Wang and Maranas, 2018, p. 462)

\section{A number of philosophical critiques}

Nevertheless, in most papers this distinction between the universality and the standardization claim is not made. Part of the explanation might be conceptual confusion or ignorance. Here, the philosopher can play a role by clarifying the conceptual confusions that are at work. In fact, multiple philosophical lessons can be drawn. Let me present two possible ways to do so, each with two examples: Georges Canguilhem and John Dupré on the one hand, Bruno Latour and Bas van Fraassen on the other. Either one could develop a metaphysical critique, following Georges Canguilhem and John Dupré, arguing that the object of minimal genome research should be reconceptualized, or one could argue from an epistemological point of view, following Bruno Latour and Bas van Fraassen, that minimal genome research has to philosophically articulate its own practice in a different way.

Firstly, and inspired by George Canguilhem, it is possible to draw a metaphysical lesson from this history, namely that living organisms are always shaped, and defined themselves, in relation to an environment. The idea of a universal minimal genome, independent from an environment, is therefore nonsensical. The main mistake, therefore, is to confuse the laboratory environment with the lack of an environment:

We must not forget that the laboratory itself constitutes a new environment in which life certainly establishes norms whose extrapolation does not work without risk when removed from the conditions to which these norms relate. For the animal and for man [sic] the laboratory environment is one possible environment among others [...] for the living being apparatuses and products are the objects among which it moves as in an unusual world. It is impossible that the ways of life in the laboratory should fail to retain any specificity in their relationship to the place and moment of the experiment. (Canguilhem, 1978, p. 85)

The work of John Dupré (2012) suggests a second and even stronger metaphysical claim: life is always fundamentally a process. The stability of living systems is rather a product of these processes and not their foundation. This thus goes a step further than Canguilhem, arguing not only that life is always defined in relation to an environment, but that the idea that there is something stable or essential in life, such as the (minimal) genome, is similarly nonsensical:

It is sometimes suggested that genome sequence might provide such an essential, continuing property for an organism. [... A] sufficient response is to note the work that the cell has to do to sustain a sufficiently accurate sequence: genome sequence is as much the consequence of organismic stability as it is its source. For a process, at any rate, no such constant property is required: persistence is something the organism achieves, not some property or properties that it continues to possess. (Dupré, 2017, p. 2) 
However, the philosophical conclusions derived from minimal genome research do not have to be metaphysical, but can also be epistemological. Thus, a third option is to argue that the history of minimal genomes confirms one of the central lessons of the work of Bruno Latour, namely that the universality of scientific claims can be achieved "only by extending the laboratory itself" (Latour, 1983, p. 151). From this Latourian perspective, one could accept that life is always relationally defined, but draw a fundamentally different conclusion: the concept of a minimal genome can make sense, but only within the laboratory. Minimal genome research can be meaningful, and minimal genomes can be found for specific settings and organisms, but biologists have to be explicit about the stabilizing work they perform in the laboratory. "No one has ever seen a laboratory fact move outside unless the lab is first brought to bear on an 'outside' situation and that situation is transformed so that it fits laboratory prescription" (Latour, 1983, p. 166).

A final and similar conclusion can be drawn from an empiricist perspective, such as that of Bas van Fraassen. The problem, according to this perspective, is that minimal genome research is infested by confused metaphysical claims about absolute universality, minimality, etc. Instead, these problems disappear once one realizes that the goal of minimal genome research should not be to find the hidden reality of minimal genomes and essential genes, but should simply be that of empirical adequacy. "Empiricism requires theories only to give a true account of what is observable, counting further postulated structure as a means to that end." (Van Fraassen, 1980, p. 3)

From that perspective, a minimal genome is merely a useful model or tool to reach empirical adequacy about existing genomes and organisms. Many of the biotechnologists working on minimal genomes are in fact good empiricists. They tend to be aware that "the phrase 'minimal gene set' in itself makes no sense, except when associated with a defined set of conditions such as species, environmental conditions (e.g., culture medium, temperature, habitat) and the purpose of the research (e.g., main for theoretical development or for bioengineering application)." (Zhang et al., 2010, p. 428) From an empiricist point of view, thus, minimal genome research would benefit from purifying its research from remaining metaphysical notions: minimal genomes must then either be seen as a theoretical tool to think about phenomena or be clearly linked to its empirical conditions in the lab.

\section{Synthetic biology as technoscience}

However, one could also argue that more than ignorance is at play, but that the research program is intentionally ambiguous: by exploiting this ambiguity between the universality claim and the standardization claim minimal genome research can portray itself as relevant, both on the level of theory development and on the level of practical applications. This strategy is not necessarily a product of mere opportunistic reasons for funding, but can also be seen as a defining element of what could be called contemporary technoscience.

Technoscience is typically defined as the blurring between science and technology. However, it could easily be argued that strong connections between science and technology have been present in the history of science for a long time (Channel, 2017) and does not differentiate recent disciplines, such as synthetic biology, nanotechnology or robotics, to which the term is often applied. A more promising candidate to characterise technoscience is therefore that its fundamental ambition is to explore possible phenomena rather than actual phenomena. Synthetic biology is a clear example of this:

Behind the rhetoric of promises used by technoscientists in their search for funding sources, their research practices are actually driven by cognitive goals. [...] Through making synthetic chromosomes or metabolic circuits, they seek knowledge about the fundamental workings of life, or possible life - extent life being often considered too 'provincial' (i.e. too particular) by synthetic biologists to support fundamental biological knowledge [...]. For instance, the construction of 
minimal cells is explicitly aimed at two intermingled objectives: tackling the fundamental question of the origin of life and providing a standard 'chassis' on which various functionalities can be implemented for predictably delivering specific performances on demand. Similarly, micromachines are designed on the model of cell motility for the dual purpose of better understanding the complex behavior of living cells and guiding tiny robots within the body for diagnostic or therapeutic actions. (Bensaude-Vincent and Loeve, 2018, p. 175)

One of the proposed characteristics of technoscience, according to the authors, is therefore a replacement of testing hypotheses with the exploration of non-actualized possibilities. Such a study of the possible thus concerns metaphysical possibilities (in contrast to, for instance, epistemic possibilities). Technoscientists are interested in exploring what can possibly exist in the world, even if it does not exist yet. This pool of non-actualized entities offers the promise of both new fundamental insights and practical applications. Moreover, to make a study of these modal properties meaningful, other methods are required, such as synthesis, which can actualize such possibilities. In contrast, a comparison between or analysis of existing genomes cannot provide an answer to which other historical alternatives were possible. At best, it could exclude certain historical possibilities by showing that they are either metaphysically impossible or that they, for instance, require sophisticated interventions by human designers, thereby excluding their occurrence in the past.

Synthetic biology is a good example of such a technoscience and is in that sense different from earlier molecular biology, including genetic engineering, which remains focused on terrestrial biology: how life has historically come to being on earth. However, synthetic biology holds the ambition of being a universal biology: a theory about any form of life, regardless of how it came to be on earth. It is thus concerned with exploring counterfactuals about how life could have been (Mann, 2013; Mariscal \& Fleming 2018; Simons forthcoming).

In other words, traditional biology still accepts the historical path dependency of terrestrial biology, whereas synthetic biology wants to break free from it and explore the physical necessities underneath the historical necessities. This can be clarified through Daniel Dennett's distinction between deep and shallow reasons for biological necessities:

The deep reasons are the constraints of the laws of physics-such as the Second Law of Thermodynamics, or the laws of mathematics or logic. The shallow reasons are just historical. There used to be two or more ways this problem might be solved, but now that some ancient historical accident has set us off down one particular path, only one way is remotely available; it has become a 'virtual necessity,' a necessity for all practical purposes, given the cards that have been dealt. The other options are no longer really options at all. (Dennett 1995, 129)

Morange offers synthetic biology as an example of a discipline mapping these deep reasons, among others "by creating new situations, and therefore allowing us to discriminate between historical constraints on one hand, and physical and design constraints on the other." (Morange 2009, 375) This message is also endorsed by synthetic biologists themselves, e.g. Elowitz and Lim (2010) when they describe synthetic biology as an "expansion of biology from a discipline that focuses on natural organisms to one that includes potential organisms" (Elowitz and Lim 2010, 889).

In a more recent article, Koskinen (2018) argues that a similar perspective is applicable to Steve Benner's work on alternative genetic systems, which makes use of what Koskinen calls how-possibly models:

In the new field of synthetic biology, researchers use how-possibly models to study what may be called potential biological systems. I argue that in the hands of bioengineers, how-possibly 
models are not just speculations or eliminable scaffolds towards one how-actually model, but rather design hypotheses for a field whose ultimate goal is to build novel biological systems and "re-wire" existing ones. Apart from their more traditional explanatory purpose, howpossibly models can function as ways of studying, and ultimately concretizing, biological possibilia. (Koskinen 2018, 494)

My claim is that such a framework also best describes most of the recent work in minimal genomes, especially the work of Craig Venter: minimal genome researchers aim to explore which minimal genomes could exist, regardless how the historically minimal genome(s) looked like (pace Morowitz).

But why did such a shift towards exploring biological possibilities, in the form of technoscientific minimal genome research, became a meaningful enterprise? There are numerous accounts of why a general shift toward technoscience has taken place, either based on internalist shifts in science due to the new role of complexity (Bonaccorsi 2010) or external and societal developments, ranging from the rise of the knowledge economy (Lyotard 1979) to the impact of the recent history of engineering and design (Simons 2020). Although shifts in society and in engineering may have been necessary conditions, my claim is that what was crucial for minimal genome research was that questions about minimal genomes became an experimentally meaningful program due to a shift in what one could call its 'experimental system' (Rheinberger, 1997). By this, I mean that new technologies transformed old, often purely speculative questions into questions that could be addressed by experimental tools in a meaningful way.

In the case of minimal genome research such crucial shifts were already hinted at above, namely the role that first comparative genomics and later synthetic genomics played in the translation of Morowitz' original, mostly speculative question about the minimal genome and the origins of life into a number of problems that could be solved by methods such as comparative genome analysis, knockout experiments, genome synthesis and genome reduction. What happened with minimal genomes is thus similar to how structures such as liposomes (spherical vesicles) gave theoretical entities such as protocells a concrete translation in chemical entities which chemists and biologists could articulate and interrogate in the laboratory. An experimental system such as a minimal genome (or a chemical protocell) is thus "a device that not only generates answers; at the same time, and as a prerequisite, it shapes the questions to be answered. An experimental system is a device to materialize questions." (Rheinberger, 1998, p. 288)

\section{Conclusion}

This article has examined how in minimal genome research a certain philosophical terminology, with notions such as minimality and essentiality, was introduced to describe its own research projects. The meaning of these terms, however, was unclear. But rather than a conceptual analysis, a historical approach was pursued to uncover what it as stake in this terminology. Specifically, four historical moments were examined: the start of minimal genome research with Harold Morowitz, the reconceptualization of minimal genomes in Mitsuhiro Itaya, Eugene Koonin and Arcady Mushegian, and finally the shift towards synthetic biology in the Venter group.

This historical survey shows a general shift away from research projects that aim to examine historical questions about life on earth or descriptive questions about specific organisms, such as mycoplasmas, towards questions that explore biological possibilities: what are possible forms of minimal genomes, regardless of whether they occur in nature, now or in the past?

This survey also highlighted a fundamental ambiguity at work in minimal genome research between what I've called the universality claim and the standardization claim: is a minimal genome supposed 
to refer to the minimal gene set for any organism, or at least any environment, thus aspiring some kind of universal biology? Or does it refer rather to a gene set that will provide stable, robust and predictable behaviour, suited for biotechnological applications? Most research in minimal genomes does not explicitly distinguish these two claims.

Two diagnoses of this ambiguity were offered. The first approach was one of philosophical clarification. The lesson drawn could be that minimal genome research is in need of a philosophical critique of its claim, either showing that it has an incorrect concept of the metaphysics of biological entities or that it has a problematic philosophical articulation of its own research practices. The second diagnosis, in contrast, stated that this ambiguity is not so much a product of error or ignorance, but rather a characteristic of contemporary technoscience and its distinctive experimental system. Technosciences, such as synthetic biology, thrive on this ambiguity, allowing them to pursue cognitive goals (such as the minimal requirements for life) and practical applications.

The first diagnosis foresees that there is a significant task left open to philosophers to examine related research projects in contemporary biology to disambiguate analogous confused claims about essentiality, necessity and universality. The second diagnosis, in contrast, predicts a different task, namely that similar ambiguities are also at play in other technoscientific disciplines, ranging from nanotechnology to contemporary work in data science. If the characterization of technoscience defended in this paper is correct, then projects in these other disciplines will, similarly to that of minimal genomes, be characterized by a combination of universality and standardization claims.

\section{Bibliography}

Acevedo-Rocha, C., Fang, G., Schmidt, M., Ussery, D., and Danchin, A. (2013). From essential to persistent genes: A functional approach to constructing synthetic life. Trends in Genetics, 29(5), 273279.

Baby, V., Lachance, J., Gagnon, J., Lucier, J., Matteau, D., Knight, T., ... Savage, D. (2018). Inferring the Minimal Genome of Mesoplasma florum by Comparative Genomics and Transposon Mutagenesis. MSystems, 3(3): 1)14.

Barnes, B., \& Dupré, J. (2008). Genomes and What to Make of Them. Chicago: University of Chicago Press.

Bedau, M., Church, G., Rasmussen, S., Caplan, A., Benner, S., Fussenegger, M., Collins, J., Deamer, D. Life after the Synthetic Cell. Nature, 465(7297), 422-424.

Bensaude-Vincent, B. (2013). Discipline-building in Synthetic Biology. Studies in History and Philosophy of Biological \& Biomedical Sciences, 44(2), 122-129.

Bensaude-Vincent, B. (2013). Discipline-building in synthetic biology. Studies in History and Philosophy of Biol \& Biomed Sci, 44(2), 122-129.

Bensaude-Vincent, B. and Loeve, S. (2018). 'Toward a Philosophy of Technosciences', in: S. Loeve, Sacha; X. Guchet \& B. Bensaude-Vincent, French Philosophy of Technology. Cham: Springer, 169-86.

Bernal, J. (1967). The Origin of Life. London: Weidenfeld and Nicolson.

Bich, L., \& Green, S. (2017). Is defining life pointless? Operational definitions at the frontiers of biology. Synthese, 195(9), 3919-3946.

Bonaccorsi, A. (2010). New forms of complementarity in science. Minerva, 48(4), 355-387. 
Boyd, R. (1999). Homeostasis, species, and higher taxa. In Species, New interdisciplinary essays, edited by R. Wilson, 141-186. Cambridge, MA: Bradford/MIT Press.

Breuer, M., Earnest, T., Merryman, C., Wise, K., Sun, L., Lynott, M., . . Luthey-Schulten, Z. (2019). Essential metabolism for a minimal cell. ELife, 8: 1-77.

Bult, C., White, O., Olsen, G., Zhou, L., Fleischmann, R., Sutton, G., . . Venter, J. (1996). Complete genome sequence of the methanogenic archaeon, Methanococcus jannaschii. Science, 273(5278), 1058-1073.

Cairns, J. \& Stent, G. \& Watson, J. (1992). (eds.) Phage and the Origins of Molecular Biology. Cold Spring Harbor (New York): Cold Spring Harbor Laboratory Press.

Canguilhem, G., (1978). On the normal and the pathological. Dordrecht: Reidel.

Channel, D. (2017). A History of Technoscience. Routledge: London.

Coyle, M., Hu, J., \& Gartner, Z. (2016). Mysteries in a Minimal Genome. ACS Central Science, 2(5), 274277.

Danchin, A. (2012). Scaling up synthetic biology: Do not forget the chassis. FEBS Letters, 586(15), 21292137.

Delaye, L., \& Moya, A. (2010). Evolution of reduced prokaryotic genomes and the minimal cell concept: Variations on a theme. BioEssays, 32(4), 281-287.

Dennett, D. (1995). Darwin's dangerous idea: Evolution and the meanings of life. New York: Simon \& Schuster.

Devitt, M. (2008). Resurrecting biological essentialism. Philosophy of Science 75 (3):344-382.

Dupré, J. (2012). Processes of life: Essays in the philosophy of biology. Oxford: Oxford university press.

Dupré, J. (2017). The metaphysics of evolution. Interface Focus, 7(5), 1-9.

Elowitz, M., \& Lim, W. (2010). Build life to understand it. Nature, 468(7326), 889.

Fleischmann, Robert D., Adams, Mark D., White, Owen, Clayton, Rebecca A., Kirkness, Ewen F., Kerlavage, Anthony R., . . Venter, J. Craig. (1995). Whole-genome random sequencing and assembly of Haemophilus influenzae Rd. Science, 269(5223), 496-512.

Foley, P., \& Shuler, M. (2010). Considerations for the design and construction of a synthetic platform cell for biotechnological applications. Biotechnology and Bioengineering, 105(1), 26-36.

Fraser, C., Gocayne, J., White, O., Adams, M., Clayton, R., Fleischmann R., . . Venter, J. (1995). The minimal gene complement of Mycoplasma genitalium. Science, 270(5235), 397-403.

Fry, I. (2006). The Origins of Research into the Origins of Life. Endeavour, 30(1), 24-28.

Gibson, D., Benders, G., Andrews-Pfannkoch, C., Denisova, E., Baden-Tillson, H., Zaveri, J., . . Smith, H. (2008). Complete chemical synthesis, assembly, and cloning of a Mycoplasma genitalium genome. Science, 319(5867), 1215-1220.

Gibson, D., Glass, J., Lartigue, C., Noskov, V., Chuang, R., Algire, M., . . Venter, J. (2010). Creation of a Bacterial Cell Controlled by a Chemically Synthesized Genome. Science, 329(5987), 52-56. 
Glass, J., Nacyra Assad-Garcia, Nina Alperovich, Shibu Yooseph, Matthew R. Lewis, Mahir Maruf, ... J. Craig Venter. (2006). Essential genes of a minimal bacterium. Proceedings of the National Academy of Sciences of the United States of America, 103(2), 425-430.

Goffeau, A., Barrell, B., Bussey, H., Davis, R., Dujon, B., Feldmann, H., . . Oliver, S. (1996). Life with 6000 genes. Science, 274(5287), 546-567.

Goodman, N. (1965). Fact, Fiction and Forecast. Indianapolis (Ind.): Bobbs-Merrill.

Griffiths, P. (1999). Squaring the circle: Natural kinds with historical essences. In Species, New interdisciplinary essays, edited by R. A. Wilson, 209-228. Cambridge, MA: Bradford/MIT Press.

Hilgartner, S. (2017). Reordering Life: Knowledge and Control in the Genomics Revolution. Cambridge, Massachusetts: The MIT Press.

Hull, D. (1965). The effect of essentialism on taxonomy: Two thousand years of stasis. The British Journal for the Philosophy of Science 15, 314-326.

Husserl, E. (1970) [1936]. The Crisis of European Sciences and Transcendental Phenomenology: An Introduction to Phenomenological Philosophy. Evanston: Northwestern University Press.

Hutchison, C., Chuang, R., Noskov, V., Assad-Garcia, N., Deerinck, T., Ellisman, M., ... Venter, J. (2016). Design and synthesis of a minimal bacterial genome. Science, 351(6280), Aad6253.

Hutchison, C., Peterson, S., Gill, S., Cline, R., White, O., Fraser, C., . . . Venter, J. (1999). Global transposon mutagenesis and a minimal Mycoplasma genome. Science, 286(5447), 2165-2169.

Huynen, M. (2000). Constructing a minimal genome. Trends in Genetics, 16(3), 116.

Itaya, M. (1995). An estimation of minimal genome size required for life. FEBS Letters, 362(3), 257-260.

Juhas, M. (2016). On the road to synthetic life: The minimal cell and genome-scale engineering. Critical Reviews in Biotechnology, 36(3), 416-423.

Keller, E. F. (1983). A Feeling for the Organism: The Life and Work of Barbara McClintock. New York: W.H. Freeman \& Company.

Koonin, E. (2000). How many genes can make a cell: The minimal-gene-set concept. Annual Review of Genomics and Human Genetics, 1, 99-116.

Koonin, E., \& Mushegian, A. (1996). Complete genome sequences of cellular life forms: Glimpses of theoretical evolutionary genomics. Current Opinion in Genetics \& Development, 6(6), 757-762.

Lartigue, C., Glass, J., Alperovich, N., Pieper, R., Parmar, P., Hutchison, C., . . Venter, J. (2007). Genome transplantation in bacteria: Changing one species to another. Science, 317(5838), 632-638.

Latour, B. (1983). Give Me a Laboratory and I will Raise the World, 141-170. In: Knorr-Cetina, K. \& Mulkay, M. (eds.) Science Observed: Perspectives on the Social Study of Science. London: Sage.

Lluch-Senar, M., Cozzuto, L., Cano, J., Delgado, J., Llórens-Rico, V., Pereyre, S., . . Serrano, L. (2015). Comparative "-omics" in Mycoplasma pneumoniae Clinical Isolates Reveals Key Virulence Factors. PLoS One, 10(9), 1-20.

Luisi, P. (2016). The emergence of Life: From chemical origins to synthetic biology (2nd ed.). Cambridge: Cambridge University Press. 
Lyotard, J. (1979). La condition postmoderne : Rapport sur le savoir. Paris: Ed. de Minuit.

Machery, E. (2011). Why I stopped worrying about the definition of life... and why you should as well. Synthese, 185(1), 145-164.

Maniloff, J., \& Morowitz, H. (1972). Cell biology of the mycoplasmas. Microbiology and Molecular Biology Reviews, 36(3), 263-90.

Mann, S. (2013). The Origins of Life: Old Problems, New Chemistries. Angewandte Chemie International Edition, 52(1), 155-162.

Mariscal, C., \& Fleming, L. (2018). Why We Should Care About Universal Biology. Biological Theory, 13(2), 121-130.

Marshall, A. (2009). The sorcerer of synthetic genomes. Nature Biotechnology, 27(12), 1121-4.

Martínez-García, E., \& De Lorenzo, V. (2016). The quest for the minimal bacterial genome. Current Opinion in Biotechnology, 42, 216-224.

Miller, S. (1953). A Production of Amino Acids under Possible Primitive Earth Conditions. Science, 117(3046), 528-529.

Mizoguchi, H., Mori, H., \& Fujio, T. (2007). Escherichia coli minimum genome factory. Biotechnology and Applied Biochemistry, 46, 157-167.

Morange, M. (2000). A History of Molecular Biology. Cambridge (Mass.): Harvard University Press.

Morange, M. (2009). Synthetic Biology: A Bridge Between Functional and Evolutionary Biology. Biological Theory, 4(4), 368-377.

Morowitz, H. (1984). The completeness of molecular biology. Israel Journal of Medical Sciences, 20(9): 750-753.

Morowitz, H. (2011). When PPLO Became Mycoplasma. American Scientist, 99(2), 102.

Mushegian, A., \& Koonin, E. (1996). A minimal gene set for cellular life derived by comparison of complete bacterial genomes. Proceedings of the National Academy of Sciences of the United States of America, 93(19), 10268-10273.

Nordmann, A. (2015) Synthetic Biology at the Limits of Science, 31-58. In: Giese, B., Pade, C., Wigger, H. \& von Gleich, A. (eds.) Synthetic Biology: Character and Impact. Cham: Springer.

Pennisi, E. (2010). Genomics. Synthetic Genome Brings New Life to Bacterium. Science, 328(5981), 958959.

Peterson, S., \& Fraser, C. (2001). The complexity of simplicity. Genome Biology, 2(2), 1-7.

Razin, S., \& Hayflick, L. (2010). Highlights of mycoplasma research-An historical perspective. Biologicals, 38(2), 183-190.

Rheinberger, H. (1997). Toward a History of Epistemic Things: Synthesizing Proteins in the Test Tube. Stanford (Calif.): Stanford University Press.

Rheinberger, H. (1998). Experimental Systems, Graphematic Spaces, 285-303. In: Lenoir, T. (ed.). Inscribing science: Scientific texts and the materiality of communication. Stanford: Stanford university press. 
Rheinberger, H. (2010). On Historicizing Epistemology: An Essay. Stanford: Stanford University Press.

Richardson, S., Mitchell, L., Stracquadanio, G., Yang, K., Dymond, J., DiCarlo, J., . . Bader, J. (2017). Design of a synthetic yeast genome. Science, 355(6329), 1040-1044.

Roberts, L. (1991). Genome patent fight erupts. Science, 254(5029), 184-186.

Shapin, S. (2008). The scientific life: a moral history of a late modern vocation. Chicago: University of Chicago.

Simons, M. (2020). The Diversity of Engineering in Synthetic Biology. Nanoethics, 14(1), 71-91.

Simons, M. (forthcoming). Dreaming of a universal biology: synthetic biology and the origins of life. HYLE - International Journal for Philosophy of Chemistry.

Smalley, D., Whiteley, M., \& Conway, T. (2003). In search of the minimal Escherichia coli genome. Trends in Microbiology, 11(1), 6-8.

Smith, H., Clyde A. Hutchison III, Cynthia Pfannkoch, \& J. Craig Venter. (2003). Generating a synthetic genome by whole genome assembly: $\phi X 174$ bacteriophage from synthetic oligonucleotides. Proceedings of the National Academy of Sciences of the United States of America, 100(26), 1544015445.

Sung, B., Choe, D., Kim, S., \& Cho, B. (2016). Construction of a minimal genome as a chassis for synthetic biology. Essays in Biochemistry, 60(4), 337-346.

Szymanski, E., \& Calvert, J. (2018). Designing with living systems in the synthetic yeast project. Nature Communications, 9(1), 2950.

Tarnopol, R., Bowden, S., Hinkle, K., Balakrishnan, K., Nishii, A., Kaczmarek, C., . . V Vecchiarelli, A. (2019). Lessons from a Minimal Genome: What Are the Essential Organizing Principles of a Cell Built from Scratch? ChemBioChem, 20(20), 2535-2545.

Van Fraassen, B. (1980). The Scientific Image. Oxford: Clarendon.

Venter, C. (2013). Life at the Speed of Light: From the Double Helix to the Dawn of Digital Life. New York: Viking.

Wallace, D. and Morowitz, H. (1973). Genome size and evolution. Chormosoma, 4O(2): 121-126.

Wang, L., \& Maranas, C. (2018). MinGenome: An In Silico Top-Down Approach for the Synthesis of Minimized Genomes. ACS Synthetic Biology, 7(2), 462-473.

Yeh, B. J. and Lim, W. A. (2007). Synthetic Biology: Lessons from the History of Synthetic Organic Chemistry. Nature Chemical Biology, 3, 521-525.

Zhang, L., Chang, S., \& Wang, J. (2010). How to make a minimal genome for synthetic minimal cell. Protein \& Cell, 1(5), 427-434. 